\title{
As falácias da secularização: análise das cinco críticas-tipo às teorias da secularização
}

Jorge Botelho Moniz'

\section{Resumo}

Não obstante as teorias da secularização marquem o debate científico na sociologia das religiões desde a década de 1960, elas têm sido fortemente criticadas desde seu advento. Em particular, criticam-se seus vieses ideológicos e históricos, sua aplicabilidade e extensão teórica e seus resultados previsíveis. Todavia, essas críticas estão, na maioria dos casos, dispersas, não tendo sido trabalhadas profunda e sistematicamente. Consideramos que, para qualquer cientista social investido no estudo da secularização, é relevante sua compilação, articulação e interpretação, de modo a poder compreender plenamente suas deficiências ou incoerências internas. Nosso trabalho pretende analisar os argumentos críticos mais sólidos e sistemáticos que foram feitos pelo estado da arte às teorias da secularização. Para isso propomos um estudo descritivo, analítico, comparativo e sincrônico dos substratos da secularização e, posteriormente, de suas críticas. Esse exame nos permite entender a fundo suas limitações proposicionais e, desse modo, sustentar a proposta de novas categorias analíticas elou empíricas ou o desenvolvimento de novas estratégias metodológicas que devem ser consideradas no contexto da modernidade múltipla e global.

Palauras-chave: Secularização. Camadas internas. Críticas-tipo. Modernidade(s).

\section{Introdução}

O momento fundamental para o estabelecimento de um estudo sistemático do fenômeno religioso nas sociedades modernas parece consensual dentro da literatura sobre a secularização.

Com efeito, a maioria dos autores menciona o período pós-II Grande Guerra (pós-1945) e o início da década de 1960 como etapas inaugurais da

I Doutorando pela Universidade Nova de Lisboa e Universidade Federal de Santa Catarina. Apoiado pelo Erasmus Mundus Action 2 Programme (União Europeia, 2014-2016) e pela FCT - Fundação para a Ciência e a Tecnologia (Portugal, desde 2016).E-mail: jobomoniz@gmail.com. 
teoria da secularização no campo da sociologia das religióes. Casanova (1994, p. 19), por exemplo, afirma que é nesse período que se podem encontrar suas primeiras tentativas de desenvolver formulaçôes empíricas e sistemáticas. Isso se deve à publicação de três livros: o Religion in Secular Society, de Bryan Wilson (1966), o Invisible Religion, de Thomas Luckmann (1967), e o The Sacred Canopy, de Peter Berger (1967). Mas, não apenas desses, segundo Demerath III (2007, p. 59), porquanto a academia das ciências sociais da época produziu uma "supersafra" de publicaçôes sobre a secularização.

O desenvolvimento teórico fez com que a tese da secularização fosse integrada, durante os anos 1960, na teoria da modernização, tornando-se um de seus axiomas centrais (GORSKI, 2003, p. 111). A tensão entre modernização e desenvolvimento religioso tornou-se, de fato, seu ponto central. Em termos muito gerais, as teorias da secularização afirmam que o processo de modernização e seus subprocessos, transformadores da totalidade da estrutura social, não podem decorrer sem consequências para as tradições e instituiçôes religiosas ${ }^{2}$. Ou seja, as propriedades estruturais da modernizaçáo, como a racionalização, a diferenciação funcional ou a societalização (Vergesellschaftung) colocam problemas à religião, pelo menos em seu sentido tradicional, e reduzem ou, no limite, extinguem sua relevância social.

Nessa época, a tese da secularização parecia autoevidente; todos pareciam concordar com a ideia de que a influência pública da religiáo estava diminuindo com o avanço da modernização (STARK, 1999, p. 251; GORSKI, 2003, p. 111). Nas reflexóes científicas sobre o lugar e futuro da religiáo no mundo moderno, a secularização foi, desde os finais da década de 1960, o paradigma dominante.

Não obstante sua proliferação e hegemonia nas ciências sociais, seus pressupostos foram progressiva e mais sistematicamente questionados, em

2 Por exemplo, a urbanização e a erosão da civilização paroquial, normalmente associadas a fortes vínculos religiosos; a expansão da literacia e da educação e o fim do monopólio do conhecimento do clero; a ciência $e$ a tecnologia e o desenvolvimento de caminhos alternativos aos religiosos para se compreender o mundo; as ideologias políticas e o surgimento de novos princípios reguladores e legitimadores da ação estatal; o crescimento do Estado moderno e a centralização de funções oferecidas anterior e unicamente pelas instituições religiosas; a participação política dos individuos e sua relativa emancipação do controle das elites políticas e religiosas; a prosperidade e a modernização econômica e o sentimento de segurança existencial que levam os indivíduos a recorrer menos à religião; a mobilidade e as migrações internacionais e o desafio que colocam aos monopólios religiosos. 
particular, nas últimas décadas do século XX. Ainda na década de 1960, alguns autores começam alertando para os vieses do conceito $^{3}$, propondo sua eliminação do discurso científico (MARTIN, 1965). Na década de 1970 questionam a tese do declínio da religião (em particular, na esfera privada, subjetiva) e apontam para a proliferaçáo do sagrado, mesmo em condiçóes de intensa modernização ${ }^{4}$. Nas décadas de 1980 e 1990 surgem algumas alternativas mais sistemáticas às teorias da secularização: os modelos da economia religiosa e da individualização. Doravante, alguns dos pressupostos principais da secularização começam a ser mais sistematicamente afrontados e reformulados. Em especial, com a ideia de que religião e modernidade são compatíveis e de que, mesmo em contextos de modernização avançada, a primeira pode prosperar por conta dos estímulos da última. Esse trabalho de aprofundamento teórico e reformulação analítica continuou desde os anos 1980 até à atualidade (HADDEN, 1987; CASANOVA, 1994; PICKEL, 2011), desenvolvendo-se, por conta da opiniáo quase generalizada de que os pressupostos da secularização não eram mais adequados para explicar a situação sociorreligiosa contemporânea.

Mas quais suas fragilidades? Ou seja, que deficiências estruturais impedem-na de observar objetivamente seu objeto de estudo e seu desenvolvimento nas sociedades modernas? Quais as críticas mais sólidas e sistemáticas que lhe foram feitas? É precisamente aqui, na tentativa de esclarecimento dessas inquietaçóes epistemológicas, que o nosso artigo se foca.

No nosso entender, tão importante quanto conhecer os principais pressupostos das teorias da secularização é estudar as críticas que lhe foram feitas e, assim, compreender suas insuficiências internas. Com efeito, a reoperacionalização científica do conceito - quer seja pela proposta de novas categorias analíticas e/ou empíricas ou pelo desenvolvimento de novas estratégias metodológicas - exige, ao cientista social, um entendimento náo superficial das limitaçóes de sua aplicação teórica. Apesar dos ganhos epistemológicos que consideramos advir de uma análise desse tipo, poucos são os estudos que lhe foram ou têm sido dedicados. E menos ainda aqueles que, pelo menos no

3 Cf. Säkularisierung: Geschichte eines ideenpolitischen Begriffs (1965) de Hermann Lübbe.

4 Cf. trabalhos The New Demons (1975) e The Return of the Sacred? (1977) de Jacques Ellul e Daniel Bell, respetivamente. 
circuito mainstream, o têm feito de forma sistemática. Todavia, quando isso ocorreu, as suas perspectivas sobre a secularização foram assaz informativas (LECHNER, 1991; SMITH, 2003; PICKEL, 2011).

Por esse motivo, propomos o exame daquilo que designamos de críticas-tipo às teorias da secularização. Não temos a pretensão de examinar todas as críticas que, até hoje, lhe foram feitas. Isso seria impossível nesse espaço de reflexão. Todavia, pretendemos observar, analisar e interpretar como se interpenetram suas críticas mais sólidas e sistemáticas. Para realizar esse desiderato, preparámos um plano de trabalho dividido, essencialmente, em três partes. Na primeira, relembramos e fazemos a súmula de alguns dos principais pressupostos e substratos das teorias da secularização. Terminada essa etapa introdutória, entramos, na segunda parte, nas suas cinco críticas-tipo. Por fim, na conclusão, avaliamos e articulamos o conteúdo principal das críticas e refletimos sobre qual o fado do debate científico sobre a secularização.

\section{Pressupostos e substratos das teorias da secularização}

Em primeiro lugar, importa notar que não existe uma única teoria $d a$ secularização. A frase designa, essencialmente, um conjunto de ideias que se refere à tensão entre modernização e religiâo. No essencial, essas teorias dizem que, à medida que os processos da modernização avançam, a tensão entre ambas tem como consequência a diminuição da relevância social da religião (BERGER, 1990 [1967]; BRUCE, 2002). Essa noção ajuda os autores a caracterizar o declínio da importância da religião e das normas e instituiçóes religiosas na vida dos indivíduos.

Os teóricos da secularização avançam, em particular, com quatro teses para justificar esse fenômeno. A discriminação dessas múltiplas teorias ou substratos da secularização é relevante, porquanto nos permite agrupar em diferentes níveis analíticos suas principais correntes científicas e assim, por meio desse refinamento metodológico, lograr uma maior clareza acerca de suas camadas internas.

A primeira é a teoria da diferenciação funcional. Fundamentalmente, diz respeito ao processo pelo qual o Estado e a política reduzem os sistemas religiosos tradicionais a um subsistema social, entre outros, fazendo-os perder sua proeminência e relevância em sociedades modernas funcionalmente 
diferenciadas. Isto é, com o crescimento da autonomia, especialização, competição e tensão entre as diferentes forças sociais, as autoridades religiosas institucionalizadas perdem o controle sobre determinadas funçóes sociais, tais como: a política, economia, educação, família, saúde ou assistência social (WILSON, 1969, p. xiv). Segundo Gorski (2000, p. 139-142), a diferenciação traz três consequências básicas, mas não estanques, para o lugar da religião na sociedade moderna: declínio, privatização e transformação. A primeira diz que com a diferenciação a sociedade deixa de necessitar das funçóes latentes da religião e, por consequência, as organizaçóes religiosas vêem sua relevância social ser circunscrita, diminuída ou até desintegrada (LUHMANN, 1995, p. 191). A segunda afirma que a diferenciação funcional deriva de uma ação política deliberada de desenvolvimento de esferas institucionais especializadas. A redução do espaço de ação e influência das instituições religiosas transformam a religiáo em uma realidade crescentemente subjetiva e privada (LUCKMANN, 1967 , p. 39-40, 85-86, 101). A última assevera que, em condiçóes de diferenciação estrutural, a religião passa a poder especializar-se exclusivamente nas suas próprias funçóes, logrando trabalhar em novos modelos de relação com os indivíduos e os Estados modernos (BERGER, 1990 [1967], p. 133; CASANOVA, 1994, p. 21).

A segunda é a teoria da racionalização. Segundo Willaime (2006, p. 763), a diferenciação constitui uma das consequências da racionalização e ambas são apontadas como fatores-chave da modernização que explicam a menor relevância da religião. Em traços gerais, a tese da racionalização, de inspiração weberiana, diz que a Reforma Protestante, o Iluminismo e a Industrialização desenvolveram uma perspectiva racional do mundo - baseada em padróes empíricos de prova, conhecimento científico dos fenômenos naturais e domínio tecnológico do universo - que fez crescer uma cosmovisão racional que, por sua vez, enfraqueceu as fundaçóes da crença no sobrenatural. Para Berger (1990 [1967], p. 105-125), esse processo teve início com o judaísmo e o cristianismo (sobretudo o protestante); enquanto, para Wilson (1976), a racionalização deriva dos avanços tecnológicos e científicos, sendo determinada por uma relação eficiente entre meios e fins, na qual qualquer pessoa pode desempenhar sua função técnica de forma autônoma. Para ambos, o que predomina são as orientaçóes racionais e empíricas do mundo, por oposição às orientaçôes mágicas e religiosas. $\mathrm{O}$ controle é técnico e burocrático e não 
moral e religioso (BERGER, 1990 [1967], p. 11, p. 20). A racionalizaçâo reduz, então, a frequência com que as pessoas e os Estados buscam direção na religiáo, especialmente em matéria educativa e em questóes de família e natalidade, mas, também, na procura de determinados objetivos sociais (WILSON, 1969, p. 63-64).

Outro elemento clássico das teorias da secularizaçáo, apontado comumente pelo estado da arte, é a passagem de um sistema de base comunitária para outro de base social; ou seja, a societalização (Vergesellschaftung). A sua versão original é a de Tönnies, na obra Gemeinschaft und Gesellschaft (1887), explicando que a transição de comunidade para sociedade reflete a perda do domínio das instituiçôes religiosas sobre o indivíduo. Essa tese foi, de forma implícita ou explícita, ecoada na literatura, designadamente por Wilson $(1976)^{5}$. O autor associa a societalizaçáo à modernizaçáo e aos seus inerentes processos de industrialização e racionalização. Segundo o argumento, a societalização refere-se ao fato de as formas de comunidade, sobre as quais a religiáo exercia anteriormente um controle social significativo, tenderem a se dissolver no processo de modernização, sendo substituídas por organizaçôes e relaçóes pessoais mais amplas e impessoais.

Aos três argumentos clássicos das teorias da secularização, indicados como elementos justificativos do decréscimo da relevância da religião, decidimos juntar o axioma da segurança existencial de Norris e Inglehart (2004). Essa adenda se afigura coerente, porquanto a sua tese parte de dois pressupostos básicos da secularização: a transição de sociedade agrária para industrial (societalização) e o desenvolvimento de uma sociedade industrial para outra pós-industrial (racionalização) (NORRIS; INGLEHART, 2004, p. 35-36). Resumidamente, o seu argumento básico defende que existe uma relação muito próxima entre o processo de modernização - os índices de desenvolvimento econômico, político e cultural - e os valores de segurança existencial ${ }^{6}$. Segundo Norris e Inglehart (2004, p. 53), a modernização reduz as ameaças

5 Cf. igualmente as obras de Danièle Hervieu-Léger: La religion en mouvement (1999) e Religion as a chain of memory (2000).

6 Para os autores, dentro desses valores de segurança deve estar, acima do desenvolvimento puramente econômico, o desenvolvimento humano. Ele se mede por meio de indicadores como: acesso igual à escolarização e à literacia, cuidados de saúde básicos, nutrição adequada, acesso à água potável ou rede social mínima para os grupos mais carentes (NORRIS; INGLEHART, 2004, p. 64). 
de sobrevivência que são comuns em sociedades em desenvolvimento, em particular entre os estratos mais pobres, e, consequentemente, esse sentimento de segurança reduz a necessidade de apelo ao amparo que a religião oferece.

A análise destes substratos permite-nos chegar a duas conclusóes básicas sobre os substratos da secularização. Primeiramente, o seu axioma central menciona que a modernização e seus concomitantes fenômenos têm um forte impacto nas esferas sociais, mas, em particular na religiosa (institucional). Em segundo lugar, não obstante os diferentes fenômenos justificativos avançados, em todos os substratos se entende que a religiáo perde espaço e plausibilidade, tornando-se uma esfera social indiferenciada e obsoleta em face dos avanços da modernização.

\section{Críticas-tipo às teorias da secularização}

Ao analisarmos os principais pressupostos e substratos das teorias da secularização, quedamo-nos com a mesma inquietação de Pickel (2011, p. 6): como é possível que essas linhas de argumento, aparentemente plausíveis, a favor da secularização tenham tão pouca receptividade nos debates recentes?

Para retorquir a essa pergunta, propomos o exame das cinco críticas-tipo às teorias da secularização que identificámos, a saber: as falácias da piedade passada, da naturalidade e inevitabilidade da secularização, de sua aplicabilidade universal, da existência de uma teoria (inquestionável) e do ocaso da religião.

Ressalvamos que nossa intenção não é discutir, individualmente, os pressupostos internos dos substratos da secularização. Ou seja, na parte precedente do trabalho, o nosso foco foi obter uma noção ampla daquilo que o estado da arte chama de teorias da secularizaçâo e, sobretudo, compreender sua estrutura interna para que, a partir daí, estivéssemos em condiçôes de passar à fase crítica. Assim sendo, as críticas que analisaremos apontam ao supracitado âmago geral das proposições da secularização, devendo ser entendidas dentro desse âmbito.

\section{I Falácia da piedade passada}

Um ponto de partida para se pensar a origem das críticas às teorias da secularização é compreender as premissas históricas do debate, nomeadamente daquilo que os críticos chamam de mito da (era de ouro da) piedade passada. 
Com efeito, segundo o estado da arte (LECHNER, 1991, p. 1106; STARK, 1999, p. 255; SWATOS; CHRISTIANO, 1999, p. 219; SMITH, 2003, p. 17-18), a tese da secularização se baseia no pressuposto de um declínio (constante) da relevância social da religiáo, sustentando a ideia de que as pessoas eram significativamente mais religiosas do que são hoje. $\mathrm{Ou}$ seja, em algum tempo (período medievo) ou lugar no passado (Europa ocidental) existiu uma era da fé na qual o mundo estava repleto de significados sagrados; porém, perante os fenômenos da modernização (da era contemporânea), ela deu lugar a uma era da razão, na qual o sagrado perde plausibilidade. Alguns exemplos dessa perspectiva podem ser encontrados na segunda metade do século XX, em particular, nas seguintes obras: The Making of the Middle Ages (1953), de Richard Southern; The World We Have Lost (1965), de Peter Laslett; Religion in Secular Society (1966) de Bryan Wilson, ou The Secular Mind (1982), de Warran Wagar. Nesses livros, grosso modo, os autores advogam o carácter fundamentalmente cristão da sociedade medieval europeia.

De acordo com Gorski (2000, p. 144), essa premissa histórica tem raízes no século XVIII, desenvolvendo-se em especial com o romantismo germânico e com a perspectiva de que a Idade Média havia sido uma época de unidade, harmonia e crença religiosa. Swatos e Christiano (1999, p. 219), por seu turno, afirmam que essa ideia é uma criação do século XIX e uma consequência da separação Estado-Igreja, do desenvolvimento dos media e da escolarização da população. Qualquer que seja o marco temporal correto, a tese da era de ouro da fé é amplamente refutada, mormente por historiadores de história medieval (STARK, 1999, p. 255). Mas não somente por eles, visto que inúmeros cientistas sociais de áreas diferentes adjetivaram de "utopia" (MARTIN, 1969 apud SMITH, 2003, p. 18), "lenda” (DELUMEAU, 1977 [1971], p. 160) ou "disparate" (DOUGLAS, 1975 apud SMITH, 2003, p. 18) a ideia de que o indivíduo pré-moderno era profundamente religioso. Por exemplo, Delumeau (1977 [1971], p. 160-161), analisando casos de superstição popular na Europa da época, conclui que, nas vésperas das Reforma Protestante, "o comum dos ocidentais era apenas muito superficialmente cristianizado". Os investigadores que seguem essa linha pretendem sublinhar os níveis de apatia, heterodoxia e agnosticismo existentes bem antes dos inícios da modernização. Eles defendem que a religião de muitas das naçóes cristãs da época era pouco profunda, possuindo uma superfície religiosa que frequentemente 
cobria uma base pouco religiosa ou mesmo irreligiosa (DEMERATH III, 2007, p. 61) ${ }^{7}$. Por esse motivo, autores como Gabriel Le Bras ou Andrew Greeley afirmam que não se pode falar de uma descristianização da Europa, porque nunca houve, em primeiro lugar, qualquer cristianização ${ }^{8}$.

Para Gorski (2000, p. 139, 2003, p. 120), a linha histórica do desenvolvimento religioso ocidental ${ }^{9}$ e a ideia de um declínio ininterrupto da religião, iniciado na Idade Média, podiam parecer defensáveis nos inícios da década de 1970 - no fecho do primeiro debate sobre a secularização -, mas que, devido às pesquisas históricas recentes, são atualmente muito menos plausíveis. Para vários autores, a concepção de que a religião encolheria e desapareceria eventualmente é um produto do meio social e cultural do seu tempo, enquadrando-se no modelo funcional evolutivo da modernização (CASANOVA, 1994, p. 16-17; NORRIS; INGLEHART, 2004, p. 11; DEMERATH III, 2007, p. 61). Ou seja, é um reflexo de padróes explicativos a-históricos e anacrônicos das teorias da secularização (PICKEL, 2011, p. 7; BLUMENBERG, 1985 [1966], p. 63 ss ), desenvolvidos por sociólogos despreocupados historicamente (STARK, 1999, p. 260).

Assim sendo, náo surpreende que os autores que trabalham com o objeto secularização sejam praticamente unânimes na afirmação de que, hoje, dificilmente se pode defender a proposição de que o cristianismo é alterado e pervertido durante a transição do período medieval para o moderno (BLUMENBERG, 1985 [1966], p. 1 ss; STARK, 1999, p. 260; SWATOS; CHRISTIANO, 1999, p. 219-220; SMITH, 2003, p. 19; PICKEL, 2011, p. 7).

\subsection{Falácias da naturalidade e da inevitabilidade}

De acordo com Blumenberg (1985 [1966], p. 77), os esforços modernos que visaram a estabelecer um forte contraste entre as épocas medieval e contemporânea deformaram a compreensão da história intelectual europeia.

\footnotetext{
7 Alguns autores - como Eamon Duffy, na obra The Stripping of the Altars (1992), ou Steve Bruce, na monografia Choice and Religion (1999) - têm uma perspectiva diferente. Os autores asseveram que, não obstante as sociedades medievais tenham sido algo vagas religiosamente e incluíssem tanto magia e animismo como o próprio cristianismo em suas crenças e práticas, elas eram sociedades religiosas.

8 Cf. Déchristianisation: Mot fallacieux (1964) e Religion as Poetry (1985), respetivamente.

9 As expressões ocidental ou ocidente e seus derivados devem ser compreendidas à luz da ideia de mundo multicivilizacional de Huntington (1996, p. 2 I ss).
} 
O pressuposto de um efeito negativo quase evolutivo da modernização na religião é uma "projeção ideológica da história” (MARTIN, 2005, p. 19) ou se assemelha a um "secularismo ideológico" (PICKEL, 2011, p. 7) que pretende examinar o mundo a partir de uma postura normativa determinista.

Com efeito, a concepção de que a secularização é um estado absorvente que, uma vez alcançado, é irreversível está muito presente na literatura (BERGER, 1990 [1967], p. 132; WILSON, 1976, p. 116; STARK, 1999, p. 253). Mais recentemente, Taylor (2007, p. 369-597) afirmou que, com a gradual modernização, supóe-se que as sociedades se tornaram menos religiosas, pelo menos, no sentido tradicional. Estaríamos vivendo em uma era secular (secular age). Ou seja, uma etapa da idade moderna na qual uma estrutura imanente das ordens cósmica, social e moral modernas se vem afirmando, progressivamente, como se o sagrado náo existisse ou como se fosse contrário aos processos de amadurecimento, crescimento e emancipação humana (TAYLOR, 2007, p. 269). Segundo Smith (2003, p. 15), nessas teorias existe um forte sentido de inevitabilidade sobredeterminista, como se os eventos históricos que conduzem à marginalização da religião fossem conduzidos por um processo natural e por um destino inexorável. Esses acontecimentos são frequentemente descritos de forma abstrata, nomeadamente através de conceitos como racionalização, diferenciação, pluralização, cientificismo ou societalização. Esse (sobre)determinismo e (sobre)abstração, ao especificarem deficientemente fatores políticos e sociais concretos, ocultam os elementos históricos que podem ter tido influência direta no fenômeno da secularização (SMITH, 2003, p. 14, 20). Como consequência, é frequentemente subtraída da história qualquer sentido de contingência; além de qualquer capacidade de agência humana (SMITH, 2003, p. 16) ${ }^{10}$. Para Smith, essa perspectiva é "teoricamente inadequada" (2003, p. 15), pois omite ou nega a importância de batalhas históricas intencionais" ${ }^{\prime \prime}$ ou de determinadas construçóes

10 De acordo com Smith (2003, p. 19-20), as teorias da secularização apenas reconhecem alguma capacidade de agência humana quando enfatizam a capacidade de autodestruição dos atores religiosos. 0 argumento é que autores como Max Weber ou Peter Berger defendem que a secularização deve ser atribuida à própria religião, em particular à racionalização do mundo promovida pelo judeocristianismo. Todavia, mais uma vez. essa concepção tende a omitir o eventual papel de relevo que outros atores sociais (arreligiosos ou irreligiosos) possam ter tido durante o processo de secularização.

II Relembrem-se alguns eventos como o humanismo renascentista europeu (séc. XIV) e os seus conceitos concomitantes como antropocentrismo, hedonismo, racionalismo ou individualismo; a Reforma Protestante (séc. 
político-sociais ${ }^{12}$ responsáveis pela criação da nossa situação atual, no que respeita ao lugar da religião na vida pública.

Por esse motivo, alguns autores asseveram que as teorias da secularização são, acima de tudo, o reflexo de uma doutrina ou ideologia institucionalizada de viés antirreligioso (MARTIN, 1965, p. 176; GLASNER, 1977, p. 64). Na expressão de Smith (2003, p. 23) ou Gorski e Altinordu (2008, p. 61), correspondem a uma ideologia pró-secular camuflada de roupagem científica. Nesse contexto, dificilmente se pode ignorar o papel desempenhado pela primeira geraçáo de sociólogos do século XIX. O estado da arte é categórico na asserção de que muitos deles não eram analistas desinteressados do seu objeto de estudo. Com efeito, estavam envolvidos em esquemas políticos e práticos para obstruir o desenvolvimento ou para promover o declínio da relevância da religiáo $^{13}$. O seu objetivo não era apenas uma compreensão teórica e desapaixonada da mudança no religioso, mas uma oportunidade de afetar o ritmo, a direção ou o resultado dessa transformação, e a tese da secularização era apenas uma manifestação intelectual desse desejo (HADDEN, 1987, p. 588-590, 607; BECKFORD, 2003, p. 41).

É precisamente aqui que situamos o âmago da segunda crítica às teorias da secularização. Smith (2003, p. 1-5) descreve-o como uma revolução secular (política); Gorski e Altinordu (2008, p. 61) como o projeto político de um movimento secularista; e Yang (2011, p. 6), mais amplamente, como uma ideologia política de crentes na secularização que mobilizaram os recursos do Estado, entre outros, para combater crenças e instituiçóes religiosas e para afastá-las da organização política, social ou cultural da sociedade. Smith

XVI); o Suppression of Religious Houses Act em Inglaterra (1530); a paz de Vestefália de I 648 e a afirmação da soberania dos Estados-nação; o triunfo do Iluminismo e da razão e da ciência no Ocidente (séc. XVIII); a revolução francesa (1789) e a laicidade ou o Reichsdeputationshauptschluss (1803) e a Säkularisation, expropriação de bens religiosos, na Alemanha; a ascensão do movimento racionalista inglês e a fundação da Sociedade Secular (185I); a Lei de separação das Igrejas e do Estado em França (1905) ou em Portugal (1911); ou ainda, de forma marcadamente mais repressiva, os regimes comunistas que emergiram na Guerra Fria na Ásia ou na Europa Central e do Leste (1948).

12 Recorde-se o que vimos em Luckmann (1967, p. 39-40, 101), no concernente à ideia de que a diferenciação funcional é fruto de uma vontade política deliberada de desenvolvimento de esferas institucionais especializadas e de redução do espaço e influência das organizações religiosas.

13 Por exemplo, Comte e a defesa do positivismo e a revolução pela ciência; Marx e o comunismo e a libertação do operariado; Durkheim e a laicidade e a emancipação pela escola laica. 
(2003, p. 2-4) enumera as características dessa revolução secular na vida pública estadunidense. Em especial, destaca o papel da ciência na produção de um novo conhecimento; do ensino (primário, médio ou superior) na transmissão objetiva, arreligiosa ou irreligiosa desse saber; da nova compreensão cultural do indivíduo que estabelece um modelo naturalístico e psicologizado da personalidade humana; da esfera judicial no estabelecimento de uma doutrina legal liberal que envolve uma estrita separação entre Estado e religião; da filosofia pública na implantação de uma república liberal processual; ou da mídia na difusão de informaçôes objetivas e neutrais. Tudo isso serviu ao propósito da privatização e marginalização e para o decréscimo da relevância das perspectivas e instituiçôes religiosas na esfera pública.

Para os críticos, esse processo - não exclusivo da realidade estadunidense - mostra que a secularização não é um produto natural e inevitável da modernização. Pelo contrário, é o resultado bem-sucedido de uma querela política, levada a cabo por uma ação voluntária de Estados e de uma elite política e intelectual. Desse modo, as teorias da secularização desempenharam o papel de uma filosofia da história e de um programa político que influencia e, provavelmente, determina o rumo das sociedades modernas ocidentais: da superstição à razão, da crença à indiferença, da religiáo à ciência ou da Igreja ao Estado.

\subsection{Falácia da aplicabilidade universal}

A questão geocivilizacional é de extrema relevância, porquanto, para os críticos, as teorias da secularização são um produto do contexto social e cultural no qual emergiram (HADDEN, 1987; ASAD, 2003; CASANOVA, 2008).

Talal Asad é particularmente relevante nesse campo, porque é um dos primeiros autores a notar que o processo histórico da secularização se desenvolve por meio de uma "inversão ideológica considerável" (2003, p. 192). Primeiramente, o secular fez parte do discurso teológico (saeculum), definindo um espaço dual (sagrado e profano) e dois tipos de clero (regular e secular); posteriormente, passou a designar um movimento filosófico de progresso humano que náo inclui a religiaao (secularismo) e outro projeto que a privatiza e discrimina, afastando suas instituiçóes e seus símbolos da esfera pública (laicidade). Como consequência dessa revolução secular, o termo deve 
ser entendido como categoria histórica e conceito universal globalizado que desponta como construção da modernidade ocidental secular (CASANOVA, 2008, p. 103).

Contudo, para Casanova (2008, p. 103-104), as atuais genealogias do vocábulo não reconhecem devidamente que a formação da secularização se encontra ligada, de forma indelével, às transformaçôes internas da cristandade europeia, da revolução papal, da Reforma Protestante ou do protestantismo evangélico estadunidense. Ou seja, não exaltam suficientemente a ideia de que a secularização se inicia e desenvolve através das mudanças de larga escala que ocorreram no Ocidente.

Essa necessidade de sublinhar a relevância das experiências políticas, sociais e religiosas ocidentais é, para Lechner (1991, p. 1116), "etnocêntrica", pois ignora as sociedades (não cristãs) nas quais esses eventos históricos tiveram um impacto relativamente reduzido. $\mathrm{O}$ argumento dos críticos é que a tese da secularização se torna problemática quando generalizada como um processo universal de desenvolvimento social e quando analisada à luz de outras áreas religiosas ou civilizacionais. Dificilmente se pode entender o conceito de secularização - no sentido do tornar terreno ou da transferência do uso eclesiástico para o civil - em sociedades com dinamismos tão divergentes, ao nível da estruturação das relaçôes e tensôes entre o espiritual e o temporal, como as confucionistas ou taoístas onde não existe, por exemplo, uma organização eclesial ${ }^{14}$. Assim sendo, como conceptualização analítica de um processo histórico, a secularização é, para Casanova (2008, p. 105), uma categoria que apenas faz sentido no contexto das dinâmicas internas e externas particulares ocorridas na cristandade europeia ocidental, desde a Idade Média.

Neste contexto, deve-se sublinhar o fato de os primeiros proponentes do conceito de secularização serem europeus (Bryan Wilson, Peter Berger ou Karel Dobbelaere). Isto é, suas obras e teorias são produto de uma herança cultural e de um sistema de ensino que levou a um eurocentrismo analítico

14 Também existem exemplos de sociedades cristãs onde o emprego do conceito clássico da secularização é, aparentemente, problemático. Nos EUA, por exemplo, os teóricos do modelo do mercado religioso - como Rodney Stark, Laurence lannaccone ou Roger Finke - defendem que a modernização e a secularização que a acompanha promovem uma competição entre firmas religiosas que tende a fomentar a vitalidade religiosa (institucional e subjetiva). 
dos padróes da secularização (SWATOS; CHRISTIANO, 1999, p. 210; CASANOVA, 2008, p. 104). Todavia, como explica Lechner (1991, p. 1114), a experiência histórica da secularização ocidental é apenas uma componente desse processo, náo podendo servir de base para uma teoria universal. Asad concorda. Para o autor, esta narrativa (euro)etnocêntrica, universal e determinista "não é mais aceitável" (ASAD, 2003, p. 1).

\subsection{Falácia da existência de teoria (inquestionável)}

De acordo com Berger (2001 apud WILLAIME, 2006, p. 770), os pressupostos da inevitabilidade e do universalismo da secularização refletem a cultura de uma elite globalizada ou a subcultura internacional de pessoas que receberam uma educação superior de tipo ocidental, em especial, nas áreas das humanidades e ciências sociais. Isso desencadeou uma imagem linear e unidirecional que dominou o pensamento ocidental, nomeadamente no campo da sociologia ${ }^{15}$.

Essa concepção assume, como vimos nas primeiras críticas, que a sociedade se move de uma condição sagrada para outra arreligiosa, na qual a religiáo recua permanentemente. O pressuposto da secularização como um fait accompli ou como um processo autoevidente que náo necessita de escrutínio científico é, portanto, outro princípio das teorias da secularização que é fortemente criticado pela literatura (BRUCE, 2002, p. 39-40; NORRIS; INGLEHART, 2004, p. 5; GORSKI; ALTINORDU, 2008, p. 74).

Martin (1965, p. 170-173) foi um dos primeiros a criticar a secularização enquanto processo linear, inevitável e universal, mas também enquanto teoria. Por um lado, alega que não existe um processo unitário de secularização; por outro, defende que, por conta da contradição entre o secular e o religioso, os conceitos de secularização adotados não oferecem qualquer conjunto de critérios que possam ser usados em uma investigação empírica. Assim sendo, o autor propóe que o conceito seja eliminado do discurso científico social, porquanto apenas havia servido funçóes meramente ideológicas, em vez de teóricas e científicas (MARTIN, 1991, p. 465 apud STARK, 1999, p. 254).

15 Vejam-se os exemplos de Charles Wright Mills, The Sociological Imagination (1959), Harvey Cox, The Secular City (1965) ou Anthony Wallace, Religion: An Anthropological View (1966). 
A perspectiva de Martin deu origem a um crescente ceticismo nos anos seguintes. Larry Shiner, analisando os (seis) sentidos do conceito de secularização, define-o como uma amálgama de ideias utilizadas dispersamente e que devem ser abandonadas ou reformuladas ${ }^{16}$. Glasner (1977, p. 64) considera-o um mito sociológico, com base em generalizaçôes retiradas de escassas descobertas empíricas e usadas pelos sociólogos para fomentar uma ideologia de progresso implícita. Fichter (1981, p. 23) cita que é um dogma praticamente inviolável da teoria sociológica que impede os sociólogos de observar a realidade religiosa das sociedades hodiernas. Já Hadden (1987, p. 588-589, 595) apresenta uma crítica mais abrangente e incisiva sobre as fraquezas das teorias da secularização, tanto de sua génese como de seus resultados presumíveis. O núcleo de seu argumento expóe que, desde sua origem, a secularização é mais uma doutrina do que uma teoria, baseando-se em máximas que caracterizam uma ideologia inquestionável (taken for granted) dos cientistas sociais, ao invés de corresponder a um conjunto sistemático de proposiçóes inter-relacionadas. Nos círculos científicos sociais, com o tempo, a ideia de secularização se sacralizou. $\mathrm{O}$ seu estatuto era táo óbvio que raramente era vista como um tópico problemático que requeria investigação empírica.

Mais recentemente, Casanova (1994, p. 17), Stark (1999, p. 251), Swatos e Christiano (1999, p. 210) e Gorski e Altinordu (2008, p. 61) também enfatizaram a carência de uma linha teórica guiadora para o conceito. Tudo isso converge naquilo que Lechner (1991, p. 1105) classifica como "a maior crítica à teoria da secularização": não existe teoria. O escrutínio cuidadoso revela que não existe de todo muita teoria ou, no mínimo, que a teoria ainda não foi sistematicamente analisada ou empiricamente testada (HADDEN, 1987, p. 599, p. 607). Tschannen (1992, p. 17) partilha dessa opinião - “a moderna teoria da secularização não existe" -; porém, considera que subsiste certa coerência ao nível paradigmático que ajuda a manter cientificamente intacta a validade do conceito (HADDEN, 1987, p. 369).

Essa congruência não implica, necessariamente, que o paradigma - i.e., o resultado inevitável (e desejável) da secularização é a privatização da religião - esteja correto. Os críticos afirmam que essa é uma "teoria pobre” (BRUCE,

16 Cf. The concept of secularization in empirical research (1967). 
2002, p. 39) que esconde a dimensão ideológica do debate (WILLAIME, 2006, p. 759). Para eles, isso reflete o que Thomas Kuhn designa por resistência à mudança de paradigma ${ }^{17}$. Ou seja, os cientistas não são facilmente distraíveis de seu foco de estudo e as anomalias que poderiam conduzir à mudança de paradigma - como o ressurgimento da religião na política internacional - têm grandes dificuldades em penetrar no conhecimento da ciência normal até ao seu âmago. A mudança de paradigma, no que respeita ao lugar da religiáo nas sociedades modernas, tem sido, nas ciências sociais em geral, mas na sociologia das religióes em particular, um processo doloroso para alguns dos defensores da secularização (YANG, 2011, p. 9). Todavia, a geração mais recente tem começado a desafiá-la.

\subsection{Falácia do ocaso da religião}

O repto supramencionado desafia diretamente o princípio primário do paradigma da secularização. A modernidade não conduz à marginalização da religião, mas à manutenção, revitalização ou, no limite, à expansão de sua influência política, social ou cultural (HALIKIOPOULOU, 2011, p. 30; PICKEL, 2011, p. 7-8; BEN-PORAT, G.; FENIGER, 2014, p. 93).

A religiáo ressurge como mecanismo dotador de sentido face à crise $d a$ modernidade. A literatura aponta, normalmente, a década de 1970 como o momento no qual a dinâmica religiosa começa se revertendo ${ }^{18}$. A partir daí, desenvolve-se a consciência acerca dos limites da secularidade e do laicismo moderno, especialmente na sua vertente científica e positivista, face à evidência de que seus efeitos não oferecem sentido à existência humana nem conduzem ao progresso integral dos indivíduos. Essa crise de sentido aparece porque os processos de modernização social, econômica e cultural romperam com as

17 Cf. The Structure of Scientific Revolutions (1962).

18 Em matéria histórica, os autores parecem coincidir nos acontecimentos essenciais para o regresso do religioso na época: as eleições israelenses de 1977 e a aclamação o Likud (direita conservadora), dando um novo impulso ao sionismo; a eleição do cardeal polaco Karol Wojtyla como novo papa da Igreja católica (1978) e o início do processo de segunda evangelização da Europa; e a revolução iraniana de 1979 que deu origem à primeira teocracia moderna. E, posteriormente, o fundamentalismo protestante nos EUA (o movimento da Maioria Moral); o budismo Sinhalese no Sri Lanka; o nacionalismo hindu na Índia; o crescimento do pentecostalismo nas Américas do Sul e Central e dos movimentos católicos no pós-comunismo da Europa do Leste; os conflitos religiosos no Balcãs entre croatas (católicos), sérvios (ortodoxos) e bósnios (muçulmanos); ou, na China, o surgimento e proliferação do movimento espiritual Falun Gong. 
fontes de identidade e com os sistemas de autoridade existentes desde há muito tempo. Em face do fracasso da modernidade, a religião ressurge então com respostas sedutoras às pessoas em busca de comunidades de sentido e de uma identidade. As coletividades religiosas aparecem como recurso fundamental para a legitimação existencial dentro de uma dinâmica social de dúvida, niilismo e anomia (KEPEL, 1991, p. 4, 11; HUNTINGTON, 1996, p. 95 ss; HALIKIOPOULOU, 2011, p. 30).

Mesmo que nas fases iniciais dos processos da modernização se possa falar de um declínio da autoridade religiosa, no longo termo, as crenças e instituiçôes religiosas mostraram resiliência e a religiâo reemergi $u^{19}$ como uma força vital nas sociedades hodiernas (BEN-PORAT; FENIGER, 2014, p. 93). $\mathrm{O}$ paradoxo encontra-se no fato de, durante largos anos, as ciências sociais terem tratado a religiáo como uma "caixa negra" (HEHIR, 2012, p. 15). Ou seja, como algo que, pela sua inescrutabilidade e irrelevância, se podia ignorar sem detrimento da análise das sociedades contemporâneas ${ }^{20}$. Todavia, os dados mostram, segundo Pierucci (1998), Berger (1999, p. 2) ou Norris e Inglehart (2004, p. 25), que o mundo, como um todo, tem hoje mais pessoas com perspectivas religiosas do que alguma vez teve e que as religióes se têm revigorado, difundido e multiplicado de forma considerável, reassumindo um lugar de influência nas sociedades contemporâneas. Os críticos passam a desafiar os vaticínios do paradigma da secularização, identificando processos sociais que o desmentem. De um lado, os intrarreligiosos, como a resistência das instituiçôes religiosas tradicionais (não obstante a sua tendência minguante), a vitalidade do islamismo, o crescimento pentecostal ou o advento e proliferaçáo de novos movimentos religiosos (geralmente formados à base de sincretismos esotéricos). De outro lado, os extrarreligiosos - supracitados na crise da modernidade - que levam ao entendimento de que a pós, segunda, alta ou ultramodernidade tem como consequência a pós-secularização (HABERMAS, 2008), a desprivatização ou repolitização do religioso (CASANOVA, 1994) ou a dessecularização (Berger, 1999).

19 Hehir (2012, p. 15) alega que não podemos falar de um verdadeiro ressurgimento, porque os assuntos religiosos nunca estiveram propriamente ausentes da agenda internacional.

20 Para Hehir (2012, p. 16-17), esse viés investigacional remonta - sobretudo política e historicamente - ao protestantismo do século XVI, à Paz de Vestefália do século XVII, às revoluções liberais do século XVIII e ao positivismo científico e à sociologia do século XIX, mas arrastou-se durante todo o século XX. 
Os termos empregados pelos autores das teorias da reversão do processo de secularização procuram, não apenas, evidenciar que a modernização não está dissolvendo a religiáo (o que, mais uma vez, torna obsoleta a tese da linearidade da secularização), mas, também, que o fenômeno religioso atual é muito mais complexo do que uma mera ressacralizaçáo (tradicional) da sociedade. É um processo de deslocação e recomposição do religioso na sociedade, no qual as tradiçôes religiosas se interpenetram com novas crenças e práticas, criando, uma situação aparentemente ambígua: os críticos não advogam o regresso ao passado religioso, nem a dissolução da secularização.

\section{Conclusão: o que fazer ao conceito de secularização?}

A análise das cinco críticas-tipo mostra que os críticos identificam problemas graves nas teorias da secularização. Essencialmente criticam o núcleo da secularização, refutando a ideia de que a religião está perecendo ou privatizando-se em razão dos avanços da modernização e, também, de que esse processo é evolutivo, universal e determinista. Ou seja, um produto natural (apolítico) e inevitável (sem controle da ação humana) das sociedades modernas.

As suas críticas concentram-se em várias áreas, nomeadamente no que diz respeito às suas premissas históricas, à matriz civilizacional que procura enquadrar universalmente a secularização, aos eventos políticos (ocultados) que a marcaram, à sua (in)capacidade teórico-analítica para interpretar o desenvolvimento de novos padróes religiosos e aos seus resultados previsíveis. O elencar dessas críticas mostra o quão desafiante que é trabalhar com o conceito de secularizaçáo e o quáo cuidadoso que deve ser o trabalho do cientista social que se dedique ao seu estudo.

A extensão, profundidade e atualidade do criticismo mostram que atingimos um ponto crucial de mudança no debate. Os acadêmicos que estudam a secularização parecem, de momento, ter poucas opçóes: largar totalmente o modelo da secularização ou mudar a direção de suas pesquisas. Em face do acúmulo de críticas náo parece causar estranheza que os autores apostem na primeira proposição. Todavia, os próprios críticos parecem relutantes em fazê-lo. Eles argumentam que, apesar de seus defeitos internos, a secularização ainda nos oferece um quadro útil para compreender a situação da religião nas sociedades modernas e, por isso, suas proposiçôes não devem ser descartadas 
levemente. Pelo contrário, é mais recompensador repensar, rever ou atualizar a secularização, à luz da realidade social contemporânea, do que abandoná-la (LECHNER, 1991, p. 1116; TSCHANNEN, 1992, p. 19; SMITH, 2003, p. 5; PICKEL, 2011, p. 15).

Neste contexto, a literatura vai apontando em duas direçóes principais. Em primeiro lugar, para a rejeição das fontes e ressonâncias míticas e ideológicas das teorias da secularização que advogam que ela é uma tendência global, uniforme e simultânea aplicável a todos os indivíduos e a todas as regiôes, religióes ou sociedades do mundo (DEMERATH III, 2007, p. 62; PICKEL, 2011, p. 4). Ou seja, renunciar a categorias analíticas de nível elevado - conceptualizaçóes universais ou teorias globais, promotoras de comparaçóes transversais entre contextos heterogéneos -, em detrimento de categorias de nível médio - conceptualizaçôes intermédias que possibilitem comparaçóes intra-área entre contextos relativamente homogéneos. Em segundo lugar, para a necessidade de se encontrarem categorias mais complexas, sofisticadas e reflexivas que nos ajudem a entender melhor o sistema global das modernidades múltiplas de Shmuel Eisenstadt. A ideia de que a relação entre modernidade e religião pode deslocar-se em várias direçóes - dependendo de fatores específicos, como o carisma de líderes espirituais particulares, o impacto de eventos contingentes ou a mobilização de movimentos baseados na fé - e que pode assumir diversas formas em contextos diferentes, obrigou os cientistas sociais a mostrarem-se mais sensíveis ao particularismo ou contexto específico da cada região ou país, mas, sobretudo, a interpretar a secularização como um fenômeno plural. Os autores falam agora de "múltiplas secularizaçôes" (MARTIN, 2005), "culturas de secularidade" (WOHLRAB-SAHR; BUCHARDT, 2012, p. 808) ou "secularização contextualizada" (PICKEL, 2011, p. 4, 15-16), afirmando que a secularização deve ser sempre entendida à luz dos distintos contextos políticos, culturais, confessionais e sócio-históricos.

Em suma, consideramos que essas propostas de análise menos deterministas e universalistas e mais finas, rigorosas e plurais são importantes para se ultrapassar os obstáculos inerentes ao modelo tradicional da secularização. No entanto, é desejável que não se concentrem somente na resposta a uma das críticas-tipo. É necessário ir mais além. Qualquer nova versão da teoria da secularização, no mínimo, 1) terá de estar menos carregada de vieses ideológicos ou 
culturais; além disso, 2) deve ser mais rigorosa na análise das especificidades religiosas e sócio-históricas dos casos de estudo; 3) precisa ser mais cautelosa na construção de conceptualizaçóes ou teorias universais; 4) deve reconhecer a força da ação humana e da contingência histórica na produção de eventuais resultados alternativos; e, por fim, se os fatos sociais indicarem uma mudança de paradigma, 5) deve ter coragem para refutar o modelo dominante.

\section{Referências}

ASAD, T. Formations of the Secular: Christianity, Islam, Modernity. Stanford: Stanford University Press, 2003.

BECKFORD, J. Social Theory and Religion, Cambridge: Cambridge University Press, 2003.

BEN-PORAT, G.; FENIGER, Y. Unpacking secularization: Structural changes, individual choices and ethnic paths. Ethnicities, v. 14, n.1, p. 91-112, 2014.

BERGER, P. [1967]. The Sacred Canopy: Elements of a Sociological Theory of Religion. Garden City, Nova Jérsia: Doubleday, 1990.

. The Desecularization of the World, a Global Overview. In: (Ed.). The

Desecularization of the World: Resurgent Religion and World Politics. Michigan: Grand Rapids, 1999. p. 1-18.

BLUMENBERG, H. [1966]. The Legitimacy of Modern Age. Tradução de Robert Wallace. Cambridge: MIT Press, 1985.

BRUCE, S. God is Dead: Secularization in the West. Cornwall: Blackwell Publishing, 2002.

CASANOVA, J. Public Religions in the Modern World. Chicago: University of Chicago Press, 1994.

Public Religions Revisited. In: VRIES, H. (Ed.). Religion: Beyond a Concept. Nova Iorque: Fordham University Press, 2008. p. 101-119.

DELUMEAU, J. [1971]. Catholicism Between Luther and Voltaire: A New View of the Counter-Reformation. Tradução de Jeremy Moiser, Londres: Burns \& Oates, 1977.

DEMERATH III, J. Secularization and Sacralization, Deconstructed and Reconstructed. In: BECKFORD, J.; DEMERATH III, J. (Ed.). The Sage Handbook of the Sociology of Religion. Londres: SAGE Publications, 2007. p. 57-80. 
FICHTER, J. Youth in search of the sacred. In: (Ed.). The Social Impact of the New

Religions. Nova Iorque: Rose of Sharon Press, 1981. p. 21-41.

GLASNER, P. The Sociology of Secularisation. A critique of a concept. Londres: Routledge \& Kegan Paul, 1977.

GORSKI, P. Historicizing the Secularization Debate: Church, State, and Society in Late Medieval and Early Modern Europe, ca. 1300 to 1700. American Sociological Review, v. 65 , n. 1 , p. $138-167,2000$.

. Historicizing the Secularization Debate: An agenda for research. In DILLON, M.

(Ed.). Handbook of the Sociology of Religion. Cambridge: Cambridge University Press, 2003. p. $110-122$.

; ALTINORDU, A. After Secularization?. The Annual Review of Sociology, v. 34, n. 55, p. 55-85, 2008.

HABERMAS, J. Between Naturalism and Religion: philosophical essays. Tradução de Ciaran Cronin, Cambridge: Polity, 2008.

HADDEN, J. Towards desacralizing secularization theory. Social Forces, v. 65, n. 3, p. 587$611,1987$.

HALIKIOPOULOU, D. Patterns of Secularization: Church, State and Nation in Greece and the Republic of Ireland. Farnham: Ashgate, 2011.

HEHIR, B. Why Religion? Why Now?. In: AAVV (Ed.). Rethinking Religion and World Affairs. Oxford: Oxford University Press, 2012. p. 15-24.

HUNTINGTON, S. The Clash of Civilizations and the Remaking of World Order. Nova Iorque: Simon \& Schuster, 1996.

KEPEL, G. La revanche de Dieu. Chrétiens, Juifs et Musulmans à la Reconquête du Monde. Paris: Le Seuil, 1991.

LECHNER, F. The Case against Secularization: A Rebuttal. Social Forces, v. 69, n. 4, p. 1103-1119, 1991.

LUCKMANN, T. The Invisible Religion: The Problem of Religion in Modern Society. Nova Iorque: Macmillan, 1967.

LUHMANN, N. Social Systems. Tradução de J. Bednarz Jr.; D. Baecker. Stanford: Stanford University Press, 1995. 
MARTIN, D. Towards Eliminating the Concept of Secularization. In: GOULD, J. (Ed.). Penguin survey of the Social Sciences. Harmondsworth: Penguin Books, 1965, p. 169-182. On Secularization: Toward a Revised General Theory. Burlington, Vt.: Ashgate, 2005.

NORRIS, P.; INGLEHART, R. Sacred and Secular: Religion and Politics Worldwide. Cambridge: Cambridge University Press, 2004.

PICKEL, G. Contextual secularization. Theoretical thoughts and empirical implications. Religion and Society in Central and Eastern Europe, v. 4, n. 1, p. 3-20, 2011.

PIERUCCI, A. F. Secularização em Max Weber. Da contemporânea serventia de voltarmos a acessar aquele velho sentido. Revista Brasileira de Ciências Sociais, v. 13, n. 37, p. 43-73, 1998.

SMITH, C. Introduction: Rethinking the secularization of American public life. In:

(Ed.). The Secular Revolution: Power, Interests, and Conflict in the Secularization of American Public Life. Berkeley: University of California Press, 2003. p. 1-96.

STARK, R. Secularization, R.I.P. Sociology of Religion, v. 60, n. 3, p. 249-273, 2009.

SWATOS, W.; CHRISTIANO, K. Secularization Theory: The Course of a Concept. Sociology of Religion, v. 60, n. 3, p. 209-228, 1999.

TAYLOR, C. A Secular Age. Cambridge: Harvard University Press, 2007.

TSCHANNEN, O. Les théories de la sécularisation. Genebra: Librairie Droz, 1992.

WILLAIME, J-P. La Sécularisation: Une exception européenne? Retour sur un concept et sa discussion en sociologie des religions. Revue Française de Sociologie, v. 47, n. 4, p. 755-783, 2006.

WILSON, B. Religion and Secular Society. A sociological comment. Londres: C. A. Watts \& Co, 1969. 1976.

Contemporary Transformation of Religion. Oxford: Oxford University Press, WOHLRAB-SAHR, M.; BUCHARDT, M. Multiples Secularities: Toward a cultural sociology of secular modernities. Comparative Sociology, v. 11, n. 6, p. 875-909, 2012.

YANG, F. Religion in China: Survival and Revival under Communist Rule. Oxford: Oxford University Press, 2012. 


\section{The secularization fallacies: analysis of five standard criticisms to secularization theories}

\section{Abstract}

Despite being part of the scientific discourse in sociology of religions since the 1960's, the theories of secularization have been heavily criticized since its advent. In particular its historical and ideological biases, its validity and theoretical extension and its expected results. However, these criticisms are, in most cases, scattered and they have not been developed deep and systematically. We believe that for any social scientist devoted to the study of secularization the compilation, articulation and interpretation of these criticisms is relevant in order to fully comprehend their internal deficiencies or incoherencies. Therefore our article aims to analyse the most solid and systematic critical arguments that have been made to secularization theories by the state of the art. For this purpose, we propose a descriptive, analytical, comparative and synchronic study of its inner layers and, then, of its criticisms. This examination allows us to get an in depth understanding of its propositional limitations and, thus, to support the proposal of new analytical and/or empirical categories or the development of new methodological strategies that ought to be considered in the context of multiple and global modernity.

Keywords: Secularization. Inner layers. Criticisms. Modernity(ies).

Recebido em: 11/10/2016

Aprovado em: 09/02/2017 